\title{
C14orf166 is a high-risk biomarker for bladder cancer and promotes bladder cancer cell proliferation
}

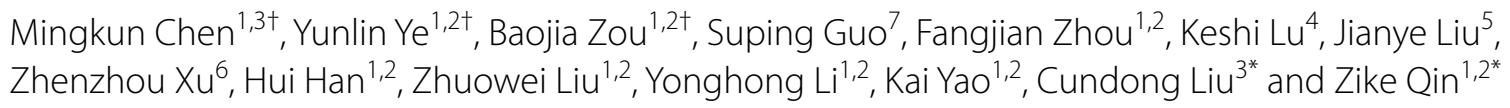

\begin{abstract}
Background: C14orf166 (chromosome 14 open reading frame 166) plays a crucial role in some tumors, but its role in bladder cancer hasn't been explored.

Method: We determined C14orf166 expression in uroepithelial cell, bladder cancer cells, normal bladder tissues and bladder cancer tissues using quantitative RT-PCR and western blot, we then analyzed the correlation between C14orf166 expression and clinicopathologic characteristics in a cohort of 149 patients with bladder cancer. Finally we downregulated C140rf166 and determined its role in the proliferation of bladder cancer cell lines using MTT assay, colony formation assay and cell cycle assay.

Results: We demonstrated C140rf166 was upregulated in bladder cancer cells and tissues, C14orf166 expression was significantly correlated with larger tumor size $(P=0.001)$, lymph node involvement $(P<0.001)$, histological differentiation $(P<0.001)$, survival time and vital states, and high $C 14$ orf 166 expression correlated with poor survival, these results suggested C14orf166 served as a high-risk marker for bladder cancer. Knockdown of C14orf166 decreased the proliferation rate and colony formation ability of bladder cancer cells, and arrested cell cycle in G1/S transition. Further analysis showed that C14orf166 knockdown caused abnormal expression of key proteins for G1/S transition, such as Cyclin D1, P21, P27 and Rb phosphorylation.
\end{abstract}

Conclusions: This study demonstrates that C14orf166 promotes bladder cancer cell proliferation and can be a novel prognostic biomarker for patients with bladder cancer.

Keywords: Bladder cancer, C14orf166, Prognosis, Cell proliferation, G1/S phase

\section{Background}

Bladder cancer is a common genitourinary tumor worldwide [1]. It is classified into two types with distinct molecular characteristics and clinical outcomes according to the tumor-node-metastasis (TNM) system. Nonmuscle-invasive bladder cancer (stage Ta, carcinoma

\footnotetext{
*Correspondence: chen_mk@sina.com; qinzk@sysucc.org.cn

${ }^{\dagger}$ Mingkun Chen, Yunlin Ye and Baojia Zou contribute equally to this work

2 Department of Urology, Cancer Center, Sun Yat-sen University,

510060 Guangzhou, Guangdong, People's Republic of China

${ }^{3}$ Department of Urology, The Third Affiliated Hospital of Southern

Medical University, 510630 Guangzhou, Guangdong, People's Republic

of China

Full list of author information is available at the end of the article
}

in situ) accounts for $60 \%$ of bladder cancer diagnoses, and morbidity is very high (50-70\%), its ability to metastasize is very low; the 5 -year survival rate is very high, i.e., up to $90 \%$. Muscle-invasive bladder cancers ( $\geq$ stage T1) have high ability to metastasize, and the 5 -year survival rate is $<50 \%[2,3]$. To date, it has been reported that some oncogenes play crucial role in the progression of bladder cancer, such as fibroblast growth factor receptor 3 (FGFR3) [4, 5], DEP domain-containing 1 (DEPDC1) [6], M-phase phosphoprotein 1 (MPHOSPH1) [7], and P73 [8]. Chemotherapy drugs have also been developed for bladder cancer therapy, such as methotrexate, vinblastine, doxorubicin, and cisplatin [9, 10]. However, survival in malignant bladder cancer is still low, and the 
therapy of bladder cancer remains a challenge. Identifying new genes that promote or suppress bladder cancer development will benefit for bladder cancer therapy.

C14orf166 (is also known CLE or CGI-99), which interacts with the PA subunit of the influenza virus polymerase complex [11], is essential in regulation of viral polymerase activity, viral RNA transcription and replication, and viral particle production [12]. Proteomics analysis has found that C14orf166 interacts with a hepatitis $\mathrm{C}$ virus core protein $(\mathrm{HCVc}), \mathrm{HCVc} 174$, suggesting that C14orf166 modulates replication and function of $\mathrm{HCV}$ [13]. Apart from its role in regulation of RNA polymerase activity, C14orf166 promotes development in some tumors. A comparison of the protein expression profiles between pancreatic cancer clinical samples found that C14orf166 levels were higher in samples with lymph node metastasis (LNM) than in non-LNM samples. This suggests that C14orf166 may promote pancreatic cancer metastasis [14]. Howng and colleagues found C14orf166 is high expression in brain tumors, and it blocked ninein phosphorylation by glycogen synthase kinase-3 $\beta$ (GSK3 $\beta$ ) [15]. Recently, C14orf166 is demonstrated to correlate with disease progression and poorer outcome in uterine cervical cancer and nasopharyngeal carcinoma [16, 17]. However, the role of C14orf166 in bladder cancer has not been investigated. JAK2/STAT3 signaling promotes bladder cancer progression [18], Xuting Chen et al. [19] found JH2 domain of JAK2 interact with C14orf166, we thought C14orf166 might regulate the progression of bladder cancer.

Here, we studied the role of C14orf166 in bladder cancer, aiming to identify a new target for bladder cancer therapy. We found that C14orf166 was upregulated in bladder cancer cells and tissues compared with normal bladder cells and tissues. High C14orf166 expression was correlated with poor patient survival, and based on analysis of the clinicopathologic characteristics, C14orf166 expression might be a novel prognostic factor for bladder cancer. Tetrazolium (MTT) and colony formation assays revealed that C14orf166 knockdown suppressed cellular proliferation, further analysis found that C14orf166 was a key regulator of G1/S transition.

\section{Methods}

\section{Cell lines and cell culture}

Bladder cancer cells J82, UM3, RT4, 5637 and T24 were cultured in RPMI 1640 medium (Gibco, Grand Island, NY, USA), supplemented with $10 \%$ fetal bovine serum (Gibco), $2 \mathrm{mM}$ L-glutamine (Gibco), $100 \mu \mathrm{M}$ non-essential amino acids (NEAA), $50 \mathrm{U} / \mathrm{mol}$ penicillin, $50 \mathrm{mg} / \mathrm{ml}$ streptomycin. Immortalized human uroepithelial cell, SV-HUC-1, was cultured in RPMI 1640 medium, supplemented with $10 \%$ fetal bovine serum, $50 \mathrm{U} / \mathrm{mol}$ penicillin and $50 \mathrm{mg} / \mathrm{ml}$ streptomycin. All of cells were purchased from American Type Culture Collection (ATCC), and were maintained in a humidified atmosphere at $37{ }^{\circ} \mathrm{C}$ with $5 \% \mathrm{CO}_{2}$.

\section{Human bladder cancer specimens}

Paraffin-embedded bladder cancer samples were obtained from a cohort of 149 Chinese patients diagnosed with bladder cancer in 2001-2012 at Cancer Center, Sun Yat-sen University, Guangdong Province, People's Republic of China. The detailed information was presented in Table 1. Clinical and pathologic factors were determined, age, gender, TNM classification, degree of differentiation, tumor number, vital states, tumor size and Recurrence were included. Six fresh bladder tumor tissues which and adjacent bladder tissues were also collected from the same place. The tissues were frozen and stored in liquid nitrogen until further use. All samples were obtained with informed consent and approved by the Guangdong General Hospital Ethics Committee.

\section{Small interfering RNAs (siRNAs), RNA extraction and quantitative RT-PCR}

In order to knock-down the expression of C14orf166, two C14orf166 siRNAs and their cognate control siRNAs (Scramble) were synthesized by Guangzhou RiboBio Co (Guangdong, China). $20 \mathrm{~nm}$ siRNA were transfected into indicated cells in six plates using Lipofectamine RNAiMax Reagent (Life Technologies) according to the manufacturer's instruction. Total RNA from cultured cells and surgical fresh bladder tumor tissues and adjacent bladder tissues were extracted using Trizol (Life technologies) according to manufacturer's instructions. cDNA was synthesized from total RNA using ReverTra Ace qPCR RT Kit (TOYOBO). Relative expressions of different genes were detected using SYBR Green PCR Kit (Roche) with the GAPDH gene as an internal reference. The PCR reactions were run using ABI 7500 Real- time PCR System. The comparative $C_{t}$ method $\left(\Delta \Delta C_{t}\right)$ was used to calculate the relative expression levels.

\section{Western blot and immunohistochemistry (IHC)}

Total protein was extracted from cells using RIPA buffer (P00013C, Beyotime), protein concentration was measured using the BCA protein assay kit (pierce). 30 ug proteins were loaded. Western blot analysis was performed as described [20]. Primary antibodies against C14orf166 (Abcam, ab188326), CyclinD1, P21, P27, retinoblastoma $(\mathrm{Rb})$ and $\mathrm{p}-\mathrm{Rb}$ were purchased from Santa Cruz Biotechnology. These antibodies were used at a dilution of 1:1000. An antibody to human $\alpha$-Tubulin (1:5000, Santa Cruz) was used as a loading control. Immunohistochemistry which was used to determine the expression of 
Table 1 Clinicopathological characteristics of clinical samples and expression of C14orf166 in Human bladder cancer

\begin{tabular}{|c|c|}
\hline Characteristics & Number of cases (\%) \\
\hline \multicolumn{2}{|l|}{ Age (years) } \\
\hline$<64$ & $81(47.1)$ \\
\hline$\geq 64$ & $91(52.9)$ \\
\hline \multicolumn{2}{|l|}{ Gender } \\
\hline Male & $156(90.7)$ \\
\hline Female & $16(9.3)$ \\
\hline \multicolumn{2}{|l|}{ T classification } \\
\hline $\mathrm{T}_{1}$ & $91(52.9)$ \\
\hline $\mathrm{T}_{2}$ & $81(47.1)$ \\
\hline \multicolumn{2}{|l|}{ N classification } \\
\hline $\mathrm{N}_{0}$ & $150(87.2)$ \\
\hline$N_{1}$ & $22(12.8)$ \\
\hline \multicolumn{2}{|l|}{ Recurrence } \\
\hline No & $82(47.7)$ \\
\hline Yes & $90(52.3)$ \\
\hline \multicolumn{2}{|c|}{ Vital status (at follow-up) } \\
\hline Alive & $67(39.0)$ \\
\hline Dead & $105(61.0)$ \\
\hline \multicolumn{2}{|c|}{ Expression of C14orf166 } \\
\hline Low expression & $87(50.6)$ \\
\hline High expression & $85(49.4)$ \\
\hline \multicolumn{2}{|l|}{ Number } \\
\hline$\geq 3$ & $64(37.2)$ \\
\hline$<3$ & $108(62.8)$ \\
\hline \multicolumn{2}{|c|}{ Histological differentiation } \\
\hline Well & $32(18.6)$ \\
\hline Moderate & $54(31.4)$ \\
\hline Poor & $86(50.0)$ \\
\hline \multicolumn{2}{|l|}{ Tumor size } \\
\hline$\geq 3 \mathrm{~cm}$ & $100(58.1)$ \\
\hline$<3 \mathrm{~cm}$ & $72(41.9)$ \\
\hline
\end{tabular}

C14orf166 in bladder cancer tissues and adjacent bladder tissues was performed according to previous report [21], anti-C14orf166 antibody (1:100, Abcam, ab188326) was used.

\section{3-(4,5-Dimethyl-2-thiazolyl)-2,5-diphenyl-2H-tetrazolium bromide (MTT) assay}

Cells, seeded on 96-well plates, were stained at indicated time points with $20 \mathrm{ul}$ sterile MTT dye $(5 \mathrm{mg} / \mathrm{ml}$, Sigma) for $4 \mathrm{~h}$ at $37{ }^{\circ} \mathrm{C}$, followed by removal of the culture medium and addition of 150ul of DMSO (Sigma). The absorbance was measured at 570 , and $655 \mathrm{~nm}$ as the reference wavelength. All experiments were performed in triplicates.

\section{Colony formation assay}

Cells were seeded on 6-well plates at a density of $0.5 \times 10^{3}$ cells per well, and cultured for 10 days. Colonies were fixed with $10 \%$ formaldehyde for $5 \mathrm{~min}$ and then stained with $1.0 \%$ crystal violet for $30 \mathrm{~s}$.

\section{Cell cycle assay}

Cell cycle assay was performed according to the standard method described previously. Briefly, cells were collected and washed by cold PBS, and fixed with $70 \%$ ethanol for overnight at $4{ }^{\circ} \mathrm{C}$, then cells were washed using cold PBS for three times, and resuspended in PBS buffer containing $100 \mathrm{U} / \mathrm{ml}$ RNase A and $50 \mathrm{ug} / \mathrm{ml} \mathrm{PI}$ at $37{ }^{\circ} \mathrm{C}$ for $30 \mathrm{~min}$. Samples were analyzed using BD FACSCalibur cytometer.

\section{Statistical analysis}

All cellular experiments were done at least three repeated, and results were described as the mean \pm standard deviation (STDEV) using SPSS version 10.0 software (SPSS, Chicago, IL. USA). Statistical differences were determined by using ANOVA and student's $t$ test for independent samples. Chi square test was used to determine the differences in the expression of C14orf166 between the two categories of tissues. It was used to calculate the $\mathrm{p}$ values to indicate the correction between clinical features and C14orf166 expression in bladder cancer. Relative risks of death associated with C14orf166 expression and other predictive variables, such as the $\mathrm{T}$ classification, were estimated by using the univariate and multivariate Cox-regression analysis. Kaplan-Meier Survival analysis and the log-rank test were used to plot overall survival curve. A p value of less than 0.05 was considered statistically significant.

\section{Results}

\section{C14orf166 expression was upregulated in bladder cancer} cell lines

To determine the role of C14orf166 in bladder cancer, we first determined C14orf166 expression in immortalized human bladder epithelial SV-HUC-1 cells and in bladder cancer cell lines. Both quantitative RT-PCR and western blotting revealed that C14orf166 was upregulated in the bladder cancer cell lines (Fig. 1a, b), suggesting that C14orf166 may contribute to the progression of bladder cancer.

\section{C14orf166 expression was upregulated in bladder cancer tissues}

We also determined C14orf166 expression in clinical samples of bladder cancer. Both quantitative RT-PCR and western blotting revealed that C14orf166 expression was higher in tumor tissues than in normal bladder tissues 


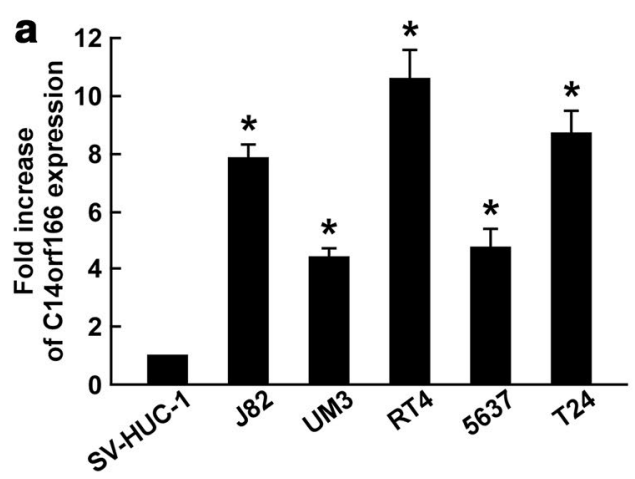

b

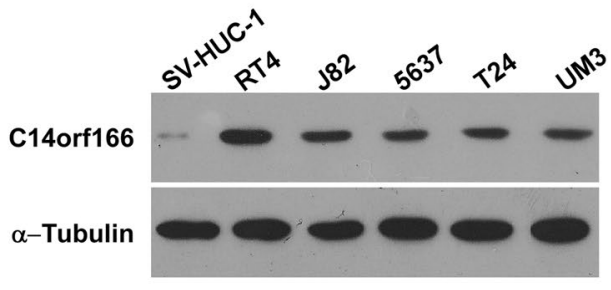

Fig. 1 C14orf166 upregulation in human bladder cancer cell lines. a Quantitative RT-PCR determination of C14orf166 expression in immortalized human bladder epithelial SV-HUC-1 cells and bladder cancer J82, UM3, RT4, 5637, and T24 cells. Transcription levels were normalized to GAPDH expression. b Western blot determination of C140rf166 expression in SV-HUC-1, J82, UM3, RT4, 5637, and T24 cells. a-Tubulin was used as the loading control. ${ }^{*} P<0.05$

(Fig. 2a). IHC determined that C14orf166 was upregulated in both $\mathrm{T} 1$ and $\mathrm{T} 2$ bladder cancer tissues compared to the normal bladder tissues, C14orf166 expression in the T2 samples was higher than that in the T1 samples
(Fig. 2b). This indicated that C14orf166 is overexpressed in patients with bladder cancer, suggesting that it may function as a new prognostic biomarker for bladder cancer.

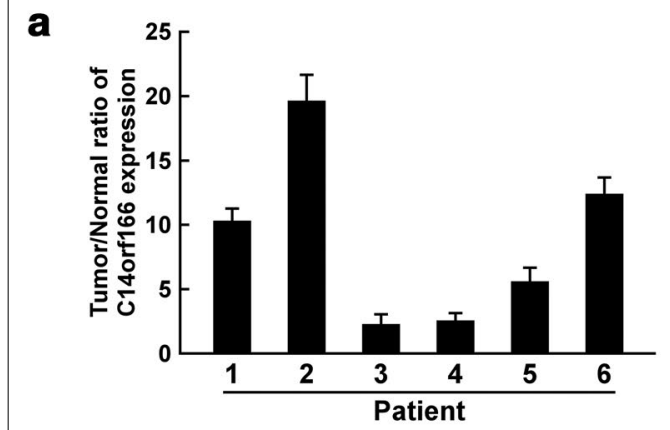

T1

C

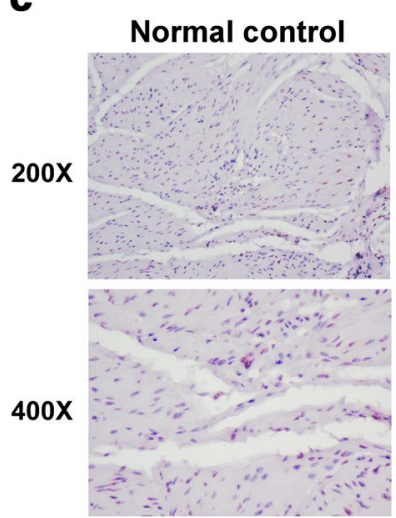

Patient1

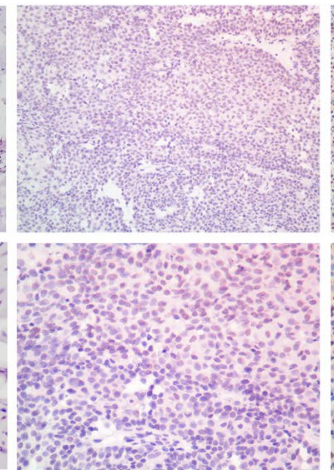

C140rf166

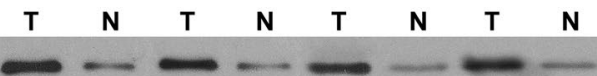

$\alpha$-Tubulin
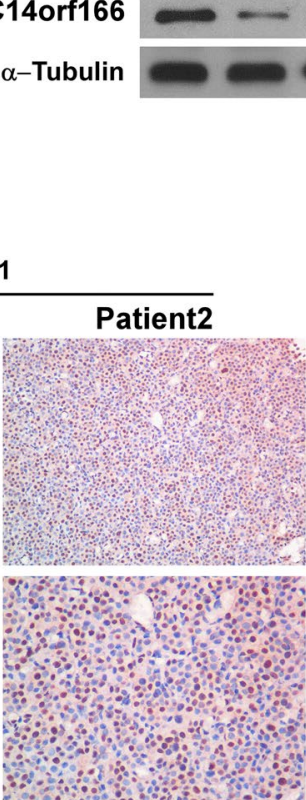

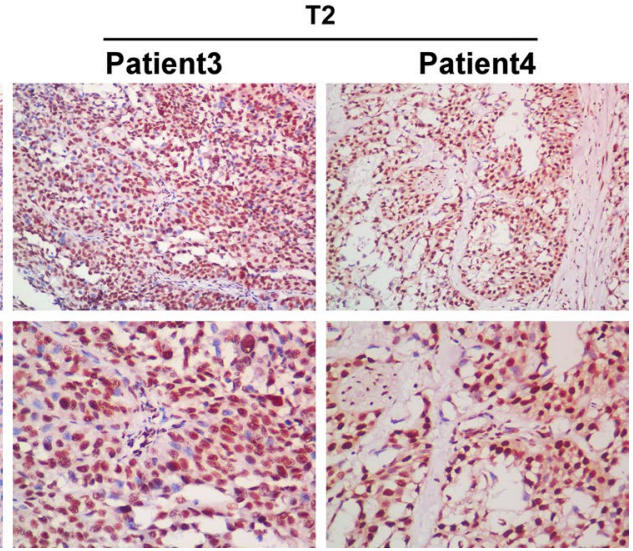

Fig. 2 C14orf166 upregulation in bladder cancer tissues. a Quantitative RT-PCR determination of C14orf166 expression in bladder cancer tissues and adjacent bladder tissues from six patients. Transcription levels were normalized to GAPDH expression. b Western blot analysis of C14orf166 expression in bladder cancer tissues and adjacent bladder tissues. a-Tubulin was used as the loading control. c $1 \mathrm{HC}$ determination of C140rf166 expression in different patients with different clinical stages of disease according to T classification (magnification: $\times 200, \times 400$ ) 
High C14orf166 expression in primary bladder cancer tissues correlated with poor patient survival

To investigate the clinical significance of C14orf166, we determined the relationships between C14orf166 expression and survival in a cohort of 149 patients with bladder cancer (Table 1). Kaplan-Meier survival analysis and the log-rank test determined that the overall survival of patients with high C14orf166 expression

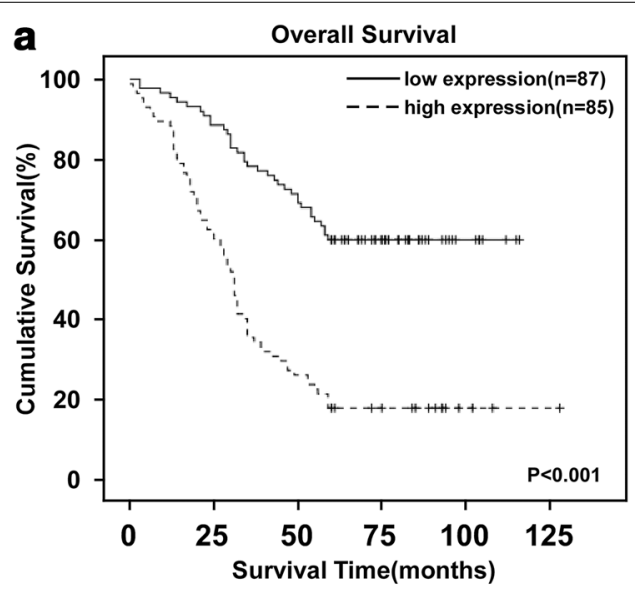

b
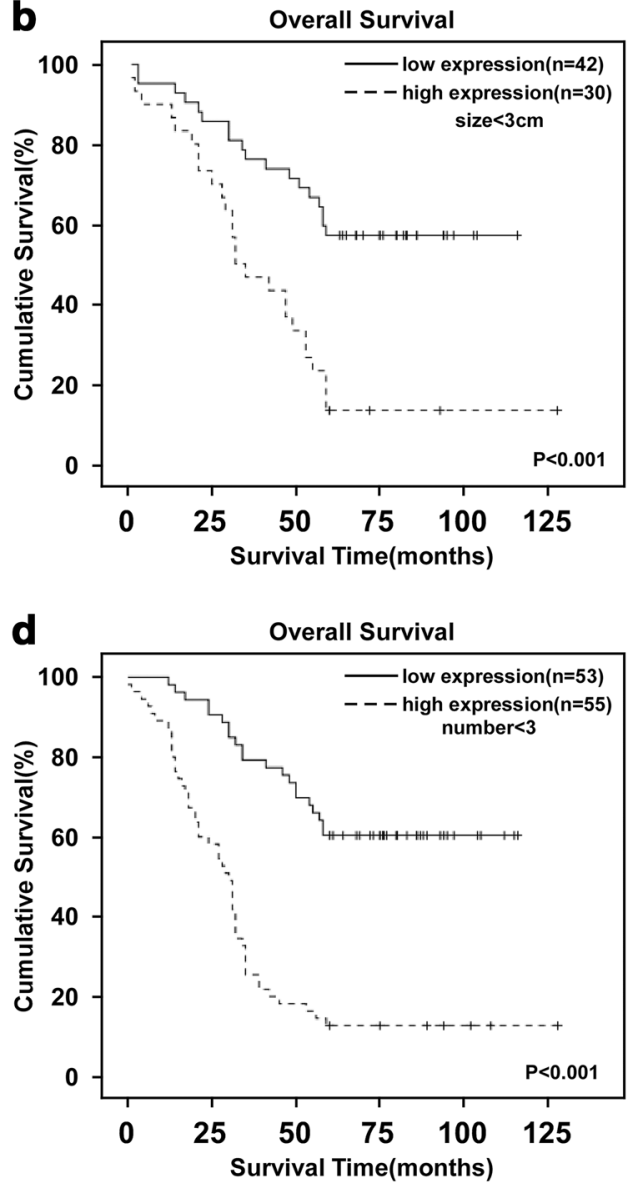

C

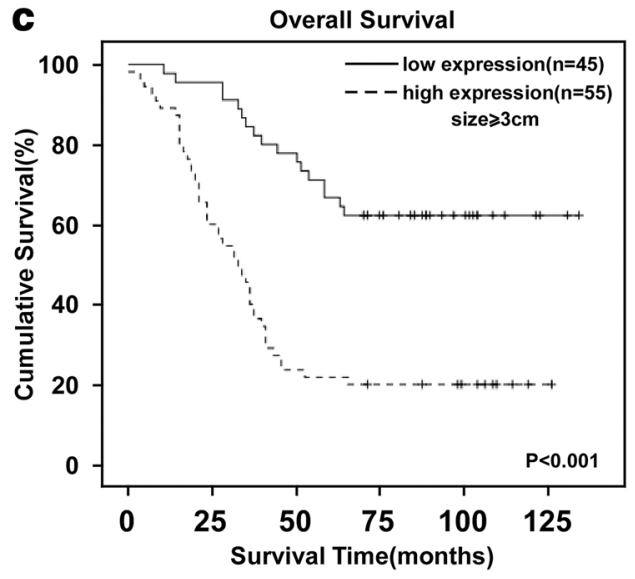

e

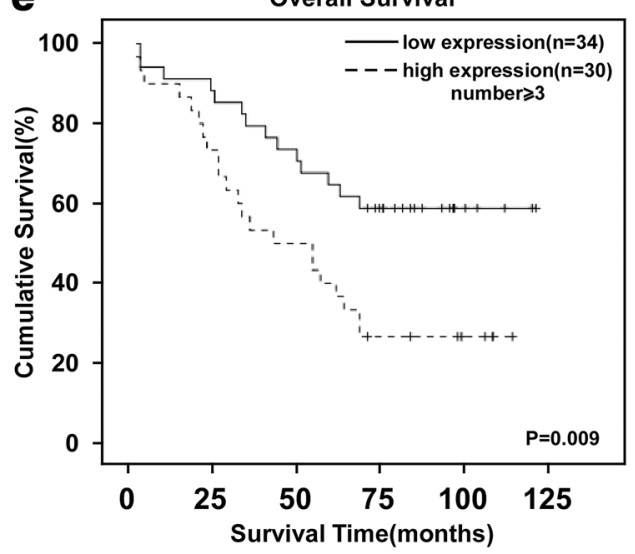

Fig. 3 Kaplan-Meier curves with log-rank tests revealed a statistical difference in overall survival. a C14orf166 expression and Kaplan-Meier analysis of overall survival $(P<0.001)$. b and $\mathbf{c} C 14$ orf166 expression and Kaplan-Meier analysis of overall survival in patients with tumor size $<3 \mathrm{~cm}$ $(P<0.001)$ (left) and with tumor size $>3 \mathrm{~cm}(P=0.008)$ (right), respectively. $\mathbf{d}$ and $\mathbf{e} C 14$ orf 166 expression and Kaplan-Meier analysis of overall survival in patients with tumor number $<3 \mathrm{~cm}(P<0.001)$ and with tumor number $>3(P=0.001)$, respectively 
Table 2 The correlation between C14orf166 expression and clinicopathologic characteristics of bladder cancer patients

\begin{tabular}{lllll}
\hline Characteristics & Total & PBOV1 & $\begin{array}{l}\text { Chi square } \\
\text { test } P \text { value }\end{array}$ \\
\cline { 3 - 4 } & & $\begin{array}{l}\text { Low } \\
\text { expression }\end{array}$ & $\begin{array}{l}\text { High } \\
\text { expression }\end{array}$
\end{tabular}

\begin{tabular}{|c|c|c|c|c|}
\hline \multicolumn{5}{|l|}{ Age (years) } \\
\hline$<64$ & 81 & 41 & 40 & 0.993 \\
\hline$\geq 64$ & 91 & 46 & 45 & \\
\hline \multicolumn{5}{|l|}{ Gender } \\
\hline Male & 156 & 78 & 78 & 0.634 \\
\hline Female & 16 & 9 & 7 & \\
\hline \multicolumn{5}{|c|}{ T classification } \\
\hline $\mathrm{T}_{1}$ & 91 & 72 & 19 & $<0.001$ \\
\hline $\mathrm{T}_{2}$ & 81 & 15 & 66 & \\
\hline \multicolumn{5}{|c|}{ N classification } \\
\hline $\mathrm{N}_{0}$ & 150 & 85 & 65 & $<0.001$ \\
\hline $\mathrm{N}_{1}$ & 22 & 2 & 20 & \\
\hline \multicolumn{5}{|l|}{ Recurrence } \\
\hline Yes & 90 & 39 & 51 & 0.046 \\
\hline No & 82 & 48 & 34 & \\
\hline \multicolumn{5}{|c|}{ Histological differentiation } \\
\hline Well & 32 & 27 & 5 & $<0.001$ \\
\hline Moderate & 54 & 42 & 12 & \\
\hline Poor & 86 & 18 & 68 & \\
\hline \multicolumn{5}{|l|}{ Number } \\
\hline$\geq 3$ & 63 & 34 & 30 & 0.608 \\
\hline$<3$ & 108 & 53 & 55 & \\
\hline \multicolumn{5}{|c|}{ Vital status (at follow-up) } \\
\hline Alive & 67 & 52 & 15 & $<0.001$ \\
\hline Dead & 105 & 35 & 70 & \\
\hline
\end{tabular}

Table 3 Spearman correlation analysis between C14orf166 and clinical pathologic factors

\begin{tabular}{lcc}
\hline Variables & \multicolumn{2}{c}{ C14orf166 expression level } \\
\cline { 2 - 3 } & Spearman correlation & P value \\
\hline Survival time & -0.413 & $<0.001$ \\
Vital status & 0.432 & $<0.001$ \\
T classification & 0.605 & $<0.001$ \\
N classification & 0.318 & $<0.001$ \\
Histological differentiation & 0.551 & $<0.001$ \\
Recurrence & 0.152 & 0.047 \\
\hline
\end{tabular}

was significantly shorter than that of patients with low C14orf166 expression (Fig. 3a). We divided the clinical samples according to the clinicopathologic characteristics, and determined patient survival. Regardless of tumor classification $\mathrm{T} 1$ and T2, patients with high
C14orf166 expression had significantly shorter survival than those with low C14orf166 expression (Fig. 3b). Regardless of tumor number $(\mathrm{n}=3)$, patients with high C14orf166 expression also had significantly shorter survival than those with low C14orf166 expression (Fig. 3c). These findings suggest that high C14orf166 expression in bladder cancer indicates poor survival.

\section{Clinical significance of C14orf166 expression in bladder cancer cases}

We determined the correlation between C14orf166 expression and the clinicopathologic characteristics of patients with bladder cancer. Tables 2 and 3 show that C14orf166 expression was significantly correlated with larger tumor size $(P=0.001)$, lymph node involvement $(P<0.001)$, histological differentiation $(P<0.001)$, survival time and vital states, which suggested a correlation between higher C14orf166 expression and clinical progression in bladder cancer. However, no significant correlation was found for other clinicopathologic characteristics such as age, sex, recurrence, and tumor number.

We also analyzed the role of C14orf166 in the prognosis of bladder cancer; we defined a relative risk of 1.000 as the baseline in patients with the following characteristics: low C14orf166 expression, T1, N0, and good histological differentiation. We used Cox regression proportional hazard analysis to determine whether C14orf166 could be used as a clinical risk factor. Univariate Cox regression analysis determined that increased C14orf166 expression was associated with significantly increased risk of death $(P<0.001)$, tumor size $(P=0.03)$, lymph node involvement $(P<0.001)$ (Table 4$)$. Multivariate Cox regression analysis found that C14orf166 predicted poor survival when C14orf166 expression, $\mathrm{T}$ classification, $\mathrm{N}$ classification, and histological differentiation were included in the analysis $(P<0.001)$. Tumor size $(P=0.023)$ and $\mathrm{N}$ classification $(P<0.001)$ also predicted unfavorable prognosis. These results suggest that C14orf166 is significantly correlated with the prognosis of bladder cancer, and is an unfavorable prognostic factor for patients with bladder cancer.

\section{C14orf166 knockdown inhibited bladder cancer cell proliferation}

To determine whether C14orf166 regulate cell proliferation, we downregulated its level by siRNAs. Western blotting and quantitative RT-PCR determined that the two siRNAs downregulated C14orf166 expression effectively in the RT4 and T24 bladder cancer cell lines compared to Scramble (Fig. 4a, b).

MTT assay revealed that C14orf166 knockdown reduced the proliferation rate of the two indicated bladder cancer cell lines (Fig. 4c). Colony formation assay determined that 
Table 4 Univariate and multivariate analyses of various prognostic parameters in patients with bladder cancer by Coxregression analysis

\begin{tabular}{|c|c|c|c|c|c|c|}
\hline & \multicolumn{3}{|c|}{ Univariate analysis } & \multicolumn{3}{|c|}{ Multivariate analysis } \\
\hline & No. patients & $P$ & $\begin{array}{l}\text { Regression } \\
\text { coefficient (SE) }\end{array}$ & $P$ & Relative risk & $\begin{array}{l}95 \% \text { Confidence } \\
\text { interval }\end{array}$ \\
\hline \multicolumn{7}{|l|}{ C14orf166 } \\
\hline Low expression & 87 & $<0.001$ & $1.697(0.312)$ & $<0.001$ & 5.456 & $2.962-0.047$ \\
\hline High expression & 85 & & & & & \\
\hline \multicolumn{7}{|l|}{ T classification } \\
\hline $\mathrm{T} 1$ & 91 & 0.010 & $-0.584(0.263)$ & 0.027 & 0.558 & $0.333-0.935$ \\
\hline $\mathrm{T} 2$ & 81 & & & & & \\
\hline \multicolumn{7}{|l|}{ N classification } \\
\hline $\mathrm{N}_{0}$ & 150 & $<0.001$ & $1.157(0.285)$ & $<0.001$ & 3.180 & $1.818-5.564$ \\
\hline $\mathrm{N}_{1}$ & 22 & & & & & \\
\hline \multicolumn{7}{|c|}{ Histological differentiation } \\
\hline Well & 32 & 0.056 & $-0.329(0.154)$ & 0.032 & 0.720 & $0.553-0.972$ \\
\hline Moderate & 54 & & & & & \\
\hline Poor & 86 & & & & & \\
\hline
\end{tabular}

downregulating C14orf166 also decreased cell numbers significantly (Fig. 4d). These results suggest that C14orf166 promotes bladder cancer cell proliferation.

\section{C14orf166 regulated bladder cancer cell proliferation by promoting $\mathrm{G} 1 / \mathrm{S}$ transition}

We further determined if C14orf166 contributes to cell proliferation through regulating cell cycle proliferation, and found knockdown of C14orf166 increased the population of G1 phase, and decreased the population of $\mathrm{S}$ phase (Fig. 5a). We further determined the expression of cell cycle regulatory proteins that control G1/S transition. We downregulated C14orf166 using siRNAs, and both quantitative RT-PCR and western blotting revealed that Cyclin D1 expression was downregulated significantly and P21 and P27 expression was upregulated significantly upon C14orf166 knockdown in RT4 bladder cancer cells. Rb phosphorylation levels were also decreased, but $\mathrm{Rb}$ expression was unaltered (Fig. 5b, c). C14orf166 knockdown in T24 cells also downregulated Cyclin D1 significantly and upregulated P21 and P27 significantly; $\mathrm{Rb}$ phosphorylation was also reduced (Fig. $5 \mathrm{~d}$, e). These results suggest that $\mathrm{C} 14$ orf166 controls cell proliferation by regulating the proteins that control G1/S transition.

\section{Discussion}

We found that C14orf166 expression is upregulated in bladder cancer cell lines and in primary bladder cancer tissues. C14orf166 promoted cell proliferation by regulating the key regulatory proteins of G1 progression. Disrupted cell cycle control is one of the primary causes of cancer development, where individuals with abnormal expression of the cell cycle control genes have increased risk for bladder cancer [22]. C14orf166 regulates the cell cycle checkpoint proteins, suggesting that it may be a key regulator of bladder cancer progression. We also demonstrated that C14orf166 was associated with clinical characteristics such as tumor size and survival time. High C14orf166 expression predicted unfavorable prognosis and low survival rate. These results suggested that C14orf166 not only functions as an oncogene but also as a novel prognostic biomarker for patients with bladder cancer. This study also demonstrated a new function of C14orf166 in tumor biology.

There are some prognostic biomarkers for bladder cancer, such as tumor protein 53 (TP53), P21, and tuberous sclerosis 1 (TSC1), but these genes only apply to a fraction of bladder cancer patients [23]. Therefore, screening new prognostic biomarkers is essential. We analyzed the relation between C14orf166 and the clinicopathologic parameters of a cohort of 172 clinical samples, and found lower survival rates in patients with high C14orf166 expression compared to patients with low C14orf166 expression. C14orf166 might combine with other clinical biomarkers to help identify patients with higher rates of survival.

C14orf166 is mapped to 14q22.1, and interacts with protein tyrosine phosphatase-interacting protein 51 (PTPIP51) to impact normal mitotic processes and chromosomal division [24]. It also interacts with human ninein (hNinein), a centrosome component, and inhibits hNinein phosphorylation, which suggests that C14orf166 may participate in centrosome architecture and regulate the formation of the centrosome, which plays a vital role in cell cycle progression, thus $\mathrm{C} 140 \mathrm{rf} 166$ may regulate cell 

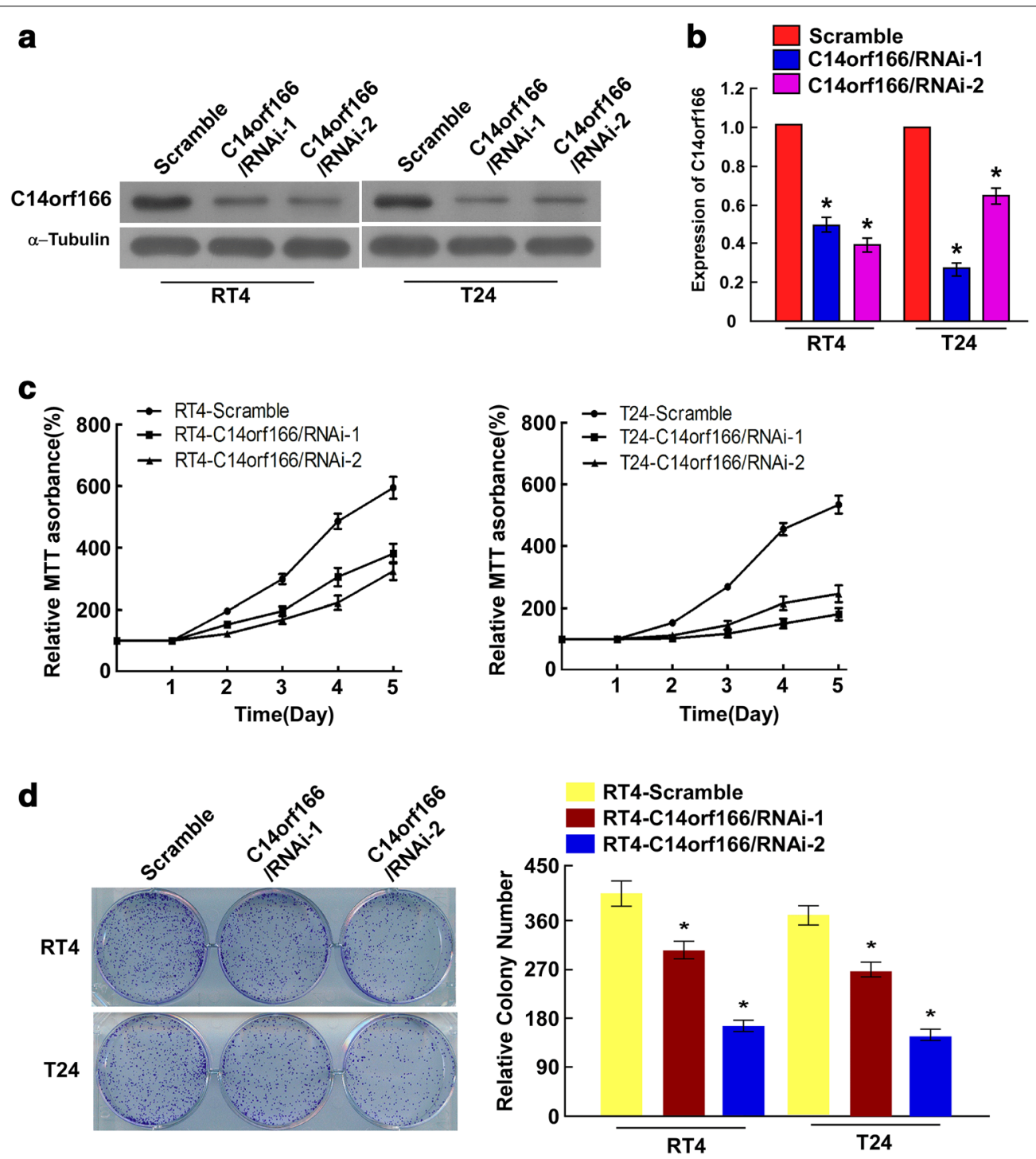

Fig. 4 C14orf166 knockdown inhibited the proliferation of bladder cancer cell lines. a Western blot determination of the effect of C14orf166 siRNAs in bladder cancer RT4 and T24 cells. b Quantitative RT-PCR determination of the effect of C14orf166 siRNAs in bladder cancer RT4 and T24 cells. Transcription levels were normalized to GAPDH expression. c MTT assay determination of bladder cancer RT4 and T24 cell proliferation following C14orf166 downregulation. d Colony formation assay determination of the effect of C14orf166 downregulation on cell proliferation. ${ }^{*} P<0.05$

cycle in this manner [15]. To test the role of C14orf166 in the progression of bladder cancer, we downregulated C14orf166 expression in bladder cancer cells, and found that C14orf166 promoted bladder cancer cell proliferation. We further analyzed the expression of key regulatory proteins of G1/S transition, finding that Cyclin D1, P21, and P27 were downregulated. Cyclin D determines the duration of the G1 phase, and is present in three subtypes: Cyclin D1, Cyclin D2, and Cyclin D3 [25]. Cyclin D1 downregulation arrests cell in $\mathrm{G} 1$ phase. Cyclin D1 also binds to cyclin-dependent kinase (CDK) 2, CDK4, and CDK6 to form an active complex that phosphorylates $\mathrm{Rb}$. Rb phosphorylation accelerates G1/S transition [26]. In our study, $\mathrm{Rb}$ phosphorylation was decreased. P21 and P27 are cyclin kinase inhibitors, which inhibit cell cycle progression [27, 28]. After C14orf166 knockdown, we found that P21 and P27 expression was upregulated. These findings suggest that C14orf166 promotes cell proliferation by accelerating G1/S transition. However, the role of C14orf166 in apoptosis and cell migration remains to be defined in vitro and in vivo. The in-depth mechanism of C14orf166 in tumorigenesis remains to be elucidated. 

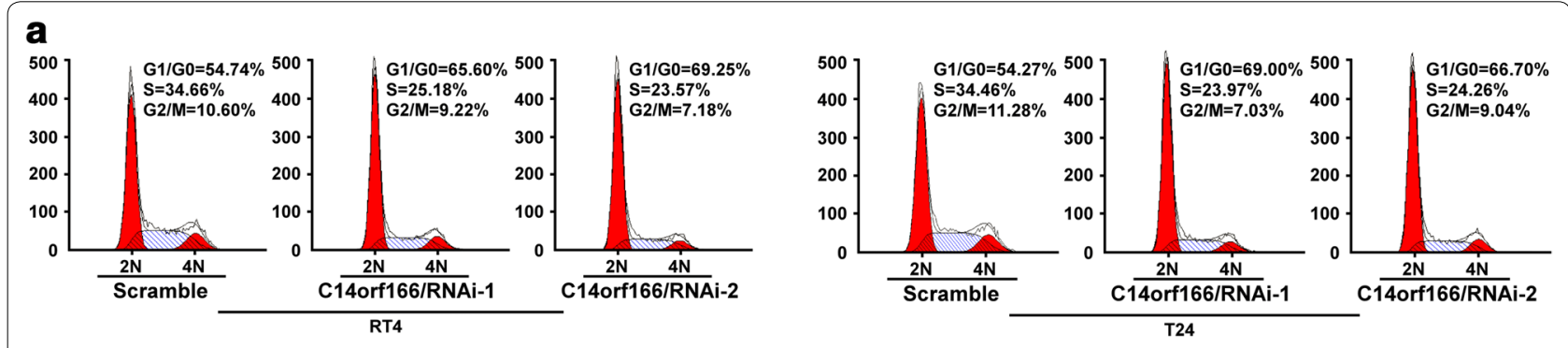

b
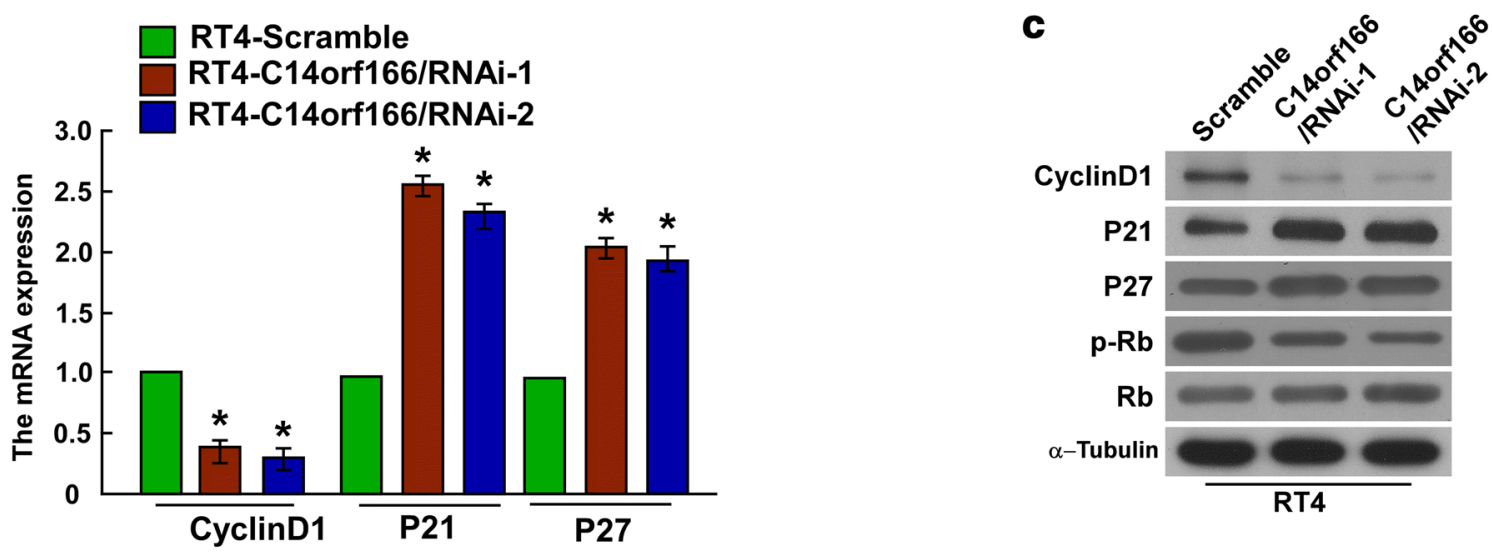

d
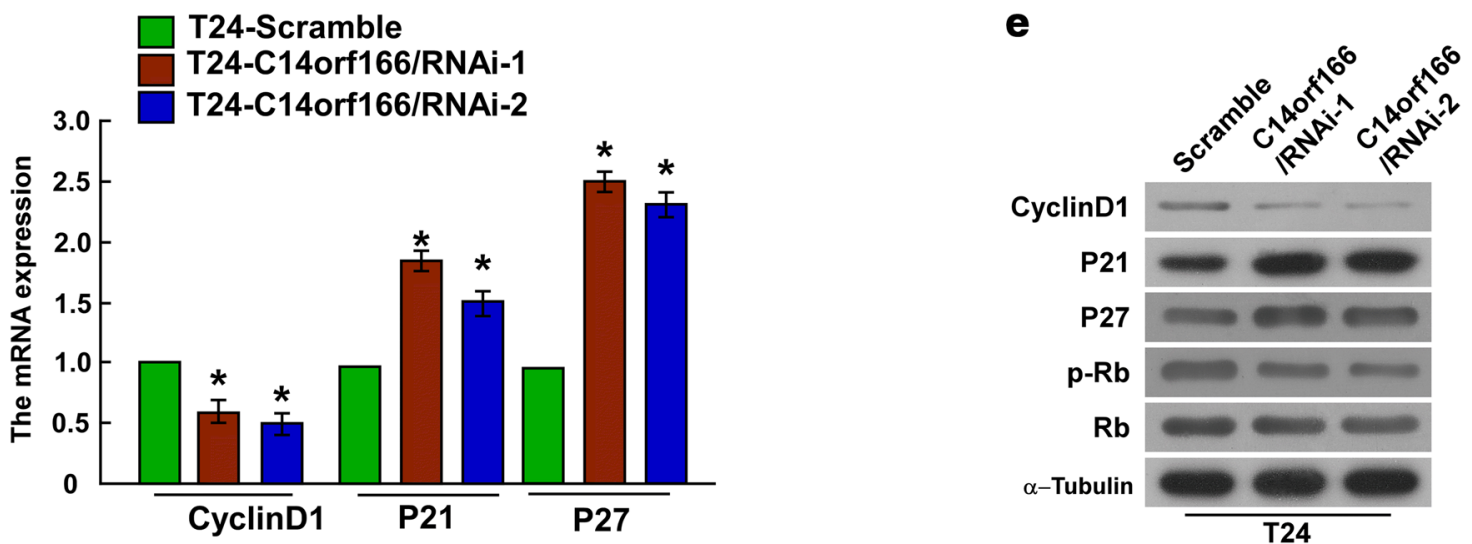

Fig. 5 C14orf166 regulated the key proteins that regulate G1/S transition. a Cell cycle assay of the effect of C14orf166 knockdown on cell cycle progression. b Quantitative RT-PCR determination of Cyclin D1, P21, and P27 expression after C14orf166 knockdown in RT4 cells. Transcription levels were normalized to GAPDH expression. c Western blot determination of Cyclin D1, p21, p27, Rb, and p-Rb expression in RT4 cells. a-Tubulin was used as the loading control. d Quantitative RT-PCR determination of Cyclin D1, P21 and P27 expression following C14orf166 knockdown in T24 cells. Transcription levels were normalized to GAPDH expression. e Western blot determination of Cyclin D1, p21, p27, Rb, and p-Rb expression in T24 cells. a-Tubulin was used as the loading control. ${ }^{*} P<0.05$

\section{Conclusions}

In summary, these data demonstrate that C14orf166 could be a prognostic factor for bladder cancer, and promotes cell proliferation by accelerating G1/S transition.

\section{Authors' contributions}

ZKQ and CDL conceived and designed the experiments, MKC, YLY, BJZ, SPG, FJZ, KSL, JYL and ZZX performed the experiments, ZKQ, CDL, MKC, YLY and

BJZ analyzed the data, MKC, YLY, BJZ, HH, ZWL, YHL and KY collected patient specimens and interpreted clinical date. ZKQ and CDL wrote the paper. All authors read and approved the final manuscript.

\section{Author details}

'State Key Laboratory of Oncology in South China, 510060 Guangzhou, Guangdong, People's Republic of China. ${ }^{2}$ Department of Urology, Cancer Center, Sun Yat-sen University, 510060 Guangzhou, Guangdong, People's Republic of China. ${ }^{3}$ Department of Urology, The Third Affiliated Hospital of Southern Medical University, 510630 Guangzhou, Guangdong, People's Republic of China. ${ }^{4}$ Department of Urology, Shenzhen Children's Hospital, 
518026 Shenzhen, Guangdong, People's Republic of China. ${ }^{5}$ Department of Urology, The Third Xiangya Hospital of Central South University, 410000 Changhsa, Hunan, People's Republic of China. ${ }^{6}$ Department of Urology, Hunan Cancer Hospital, 410000 Changsha, Hunan, People's Republic of China. ${ }^{7}$ Department of Radiotherapy, Cancer Center, Sun Yat-sen University, 510060 Guangzhou, Guangdong, People's Republic of China.

\section{Acknowledgements}

This work was supported by the National Natural Science Foundation of China, No. 81072101/h1619, Southern Medical University outstanding young scientific and technical personnel cultivation project No. PY2013N064 and Natural Science Foundation of Guangdong Province - doctoral startup project No. 2014A030310017.

\section{Competing interests}

The authors declare that they have no competing interests.

Received: 3 July 2015 Accepted: 27 January 2016

Published online: 23 February 2016

\section{References}

1. Ferlay J, Shin HR, Bray F, Forman D, Mathers C, Parkin DM. Estimates of worldwide burden of cancer in 2008: GLOBOCAN 2008. Int J Cancer. 2010:127(12):2893-917.

2. Knowles MA, Hurst CD. Molecular biology of bladder cancer: new insights into pathogenesis and clinical diversity. Nat Rev Cancer. 2014;15(1):25-41.

3. Choi W, Czerniak B, Ochoa A, Su X, Siefker-Radtke A, Dinney C, McConkey DJ. Intrinsic basal and luminal subtypes of muscle-invasive bladder cancer. Nat Rev Urol. 2014;11(7):400-10.

4. Kiemeney LA, Sulem P, Besenbacher S, Vermeulen SH, Sigurdsson A, Thorleifsson G, Gudbjartsson DF, Stacey SN, Gudmundsson J, Zanon C, et al. A sequence variant at $4 p 16.3$ confers susceptibility to urinary bladder cancer. Nat Genet. 2010;42(5):415-9.

5. Wang M, Chu H, Yan F, Qin C, Li P, Yuan L, Yin C, Xu J, Zhang Z. Chromosome 4p16.3 variant modify bladder cancer risk in a Chinese population. Carcinogenesis. 2011;32(6):872-5.

6. Kanehira M, Harada Y, Takata R, Shuin T, Miki T, Fujioka T, Nakamura Y, Katagiri T. Involvement of upregulation of DEPDC1 (DEP domain containing 1) in bladder carcinogenesis. Oncogene. 2007;26(44):6448-55.

7. Kanehira M, Katagiri T, Shimo A, Takata R, Shuin T, Miki T, Fujioka T, Nakamura Y. Oncogenic role of MPHOSPH1, a cancer-testis antigen specific to human bladder cancer. Cancer Res. 2007:67(7):3276-85.

8. Yokomizo A, Mai M, Tindall DJ, Cheng L, Bostwick DG, Naito S, Smith DI, Liu W. Overexpression of the wild type p73 gene in human bladder cancer. Oncogene. 1999;18(8):1629-33.

9. Pouessel D, Gauthier H, Serrate C, Pfister C, Culine S. Dose-dense methotrexate, vinblastine, Doxorubicin, and Cisplatin neoadjuvant chemotherapy in bladder cancer: ready for prime time? J Clin Oncol. 2014;32(36):4168-9.

10. Adesunloye BA. Neoadjuvant Phase II Studies of Modified Methotrexate, Vinblastine, Doxorubicin, and Cisplatin in Muscle-Invasive Bladder Cancer. J Clin Oncol. 2014;32(36):4170.

11. Huarte M, Sanz-Ezquerro JJ, Roncal F, Ortin J, Nieto A. PA subunit from influenza virus polymerase complex interacts with a cellular protein with homology to a family of transcriptional activators. J Virol. 2001;75(18):8597-604.
12. Rodriguez A, Perez-Gonzalez A, Nieto A. Cellular Human CLE/C14orf166 Protein Interacts with Influenza Virus Polymerase and Is Required for Vira Replication. J Virol. 2011;85(22):12062-6.

13. Lee JW, Liao PC, Young KC, Chang CL, Chen SSL, Chang TT, Lai MD, Wang SW. Identification of hnRNPH1, NF45, and C14orf166 as Novel Host Interacting Partners of the Mature Hepatitis C Virus Core Protein. J Proteome Res. 2011;10(10):4522-34

14. Cui Y, Wu J, Zong M, Song G, Jia Q, Jiang J, Han J. Proteomic profiling in pancreatic cancer with and without lymph node metastasis. Int J Cancer. 2009;124(7):1614-21.

15. Howng SL, Hsu HC, Cheng TS, Lee YL, Chang LK, Lu PJ, Hong YR. A novel ninein-interaction protein, CGl-99, blocks ninein phosphorylation by GSK3beta and is highly expressed in brain tumors. FEBS Lett. 2004;566(1-3):162-8.

16. Zhang W, Ou J, Lei F, Hou T, Wu S, Niu C, Xu L, Zhang Y. C14ORF166 overexpression is associated with pelvic lymph node metastasis and poor prognosis in uterine cervical cancer. Tumour biol. 2015.

17. Yang L, Li F, Lei F, Wang Y, Wu S, Song L, Chen Y. Overexpression of chromosome 14 open reading frame 166 correlates with disease progression and poorer prognosis in human NPC. Tumour Biol. 2015;36(10):7977-86.

18. Joung YH, Na YM, Yoo YB, Darvin P, Sp N, Kang DY, Kim SY, Kim HS, Choi $\mathrm{YH}$, Lee HK, et al. Combination of AG490, a Jak2 inhibitor, and methylsulfonylmethane synergistically suppresses bladder tumor growth via the Jak2/STAT3 pathway. Int J Oncol. 2014;44(3):883-95.

19. Chen X, Ying Z, Lin X, Lin H, Wu J, Li M, Song L. Acylglycerol kinase augments JAK2/STAT3 signaling in esophageal squamous cells. J Clin Investig. 2013;123(6):2576-89.

20. Katayama K, Nakamura A, Sugimoto Y, Tsuruo T, Fujita N. FOXO transcription factor-dependent p15(INK4b) and p19(INK4d) expression. Oncogene. 2008;27(12):1677-86.

21. Guo BH, Feng Y, Zhang R, Xu LH, Li MZ, Kung HF, Song LB, Zeng MS. Bmi-1 promotes invasion and metastasis, and its elevated expression is correlated with an advanced stage of breast cancer. Mol Cancer. 2011;10:10.

22. Wu X, Gu J, Grossman HB, Amos Cl, Etzel C, Huang M, Zhang Q, Millikan $\mathrm{RE}$, Lerner S, Dinney CP, et al. Bladder cancer predisposition: a multigenic approach to DNA-repair and cell-cycle-control genes. Am J Hum Genet. 2006;78(3):464-79.

23. Ye F, Wang L, Castillo-Martin M, McBride R, Galsky MD, Zhu J, Boffetta P, Zhang DY, Cordon-Cardo C. Biomarkers for bladder cancer management: present and future. Am J Clin Exp Urol. 2014;2(1):1-14.

24. Brobeil A, Graf M, Eiber M, Wimmer M. Interaction of PTPIP51 with Tubulin, CGl-99 and Nuf2 During Cell Cycle Progression. Biomolecules. 2012;2(1):122-42.

25. Lapenna S, Giordano A. Cell cycle kinases as therapeutic targets for cancer. Nat Rev Drug Discov. 2009;8(7):547-66.

26. Sherr CJ, McCormick F. The RB and p53 pathways in cancer. Cancer Cell. 2002;2(2):103-12

27. Chu IM, Hengst L, Slingerland JM. The Cdk inhibitor p27 in human cancer: prognostic potential and relevance to anticancer therapy. Nat Rev Cancer. 2008;8(4):253-67.

28. Kumar R, Gururaj AE, Barnes CJ. p21-activated kinases in cancer. Nat Rev Cancer. 2006;6(6):459-71.

\section{Submit your next manuscript to BioMed Central and we will help you at every step:}

- We accept pre-submission inquiries

- Our selector tool helps you to find the most relevant journal

- We provide round the clock customer support

- Convenient online submission

- Thorough peer review

- Inclusion in PubMed and all major indexing services

- Maximum visibility for your research

Submit your manuscript at www.biomedcentral.com/submit
() Biomed Central 